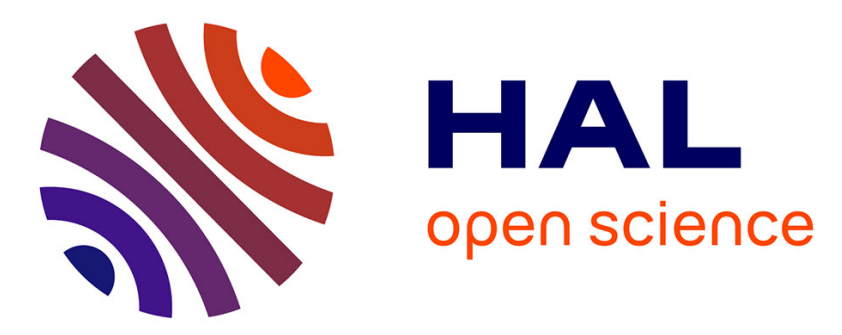

\title{
A computational approach for the fatigue design of threaded connections
}

\author{
Mohamed Ferjani, Daniel Averbuch, Andrei Constantinescu
}

\section{To cite this version:}

Mohamed Ferjani, Daniel Averbuch, Andrei Constantinescu. A computational approach for the fatigue design of threaded connections. International Journal of Fatigue, 2011, 33, pp. 610-623. 10.1016/j.ijfatigue.2010.11.006 . hal-00544296

\section{HAL Id: hal-00544296 \\ https://hal-polytechnique.archives-ouvertes.fr/hal-00544296}

Submitted on 7 Dec 2010

HAL is a multi-disciplinary open access archive for the deposit and dissemination of scientific research documents, whether they are published or not. The documents may come from teaching and research institutions in France or abroad, or from public or private research centers.
L'archive ouverte pluridisciplinaire HAL, est destinée au dépôt et à la diffusion de documents scientifiques de niveau recherche, publiés ou non, émanant des établissements d'enseignement et de recherche français ou étrangers, des laboratoires publics ou privés. 


\title{
A computational approach for the fatigue design of threaded connections.
}

\author{
Mohamed Ferjani ${ }^{\mathrm{a}, \mathrm{b}}$ Daniel Averbuch ${ }^{\mathrm{b}}$ Andreï Constantinescu ${ }^{\mathrm{a}}$ \\ ${ }^{a}$ Solid Mechanics Laboratory - CNRS UMR 7649, \\ Department of Mechanics - Ecole Polytechnique, \\ 91128 Palaiseau cedex, France \\ ${ }^{\mathrm{b}}$ IFP Energies nouvelles, \\ Rond-point de l'échangeur de Solaize, \\ BP 3, 69360 Solaize, France \\ Corresponding author : Andreï Constantinescu \\ andrei.constantinescu@lms.polytechnique.fr, \\ tel : (33) 169335756
}

\begin{abstract}
The aim of this paper is to propose a lifetime prediction method for threaded connections. The example discussed here is a drillstring connection used in the oil and gas industry. The method is based on a mechanical analysis performed either with finite elements or a closedform solution described in a companion paper, and a fatigue analysis using the Dang Van criterion which has been extended to finite life domain. The mechanical analysis provides the stabilized stress path and the fatigue analysis provides the fatigue life. Fatigue tests have been performed on small scale threaded connections in order to validate the methodology. The comparisons with the predictions show the difficulties to estimate the fatigue life on structures presenting high stress gradient due to scale effects.
\end{abstract}

Key words:

High Cycle Fatigue, notch, critical distance, Dang Van criterion, threaded connection, closed-form solution.

\section{List of symbols}

Preprint submitted to International Journal of Fatigue 


\begin{tabular}{|c|c|}
\hline LET & Last Engaged Thread \\
\hline FET & First Engaged Thread \\
\hline$\underline{\underline{\Sigma}}$ & macroscopic stress field (scale of the connection) \\
\hline$\tau$ & mesoscopic shear stress (scale of the grain of metal) \\
\hline$P$ & hydrostatic pressure \\
\hline$a_{N}, b_{N}$ & parameters of the Dang Van criterion \\
\hline$N$ & number of cycles to initiate a crack \\
\hline$C_{u p}$ & Make-Up torque \\
\hline $\mathrm{f}$ & friction coefficient \\
\hline$Q_{u p}$ & resultant of the contact pressure at the shoulder \\
\hline & due to the Make-Up torque \\
\hline$\Sigma_{u p}$ & minimum uniform applied stress at loss of contact at the shoulder \\
\hline$K_{Z Z}^{t}$ & axial stress concentration factor for tension loading \\
\hline$K_{Z Z}^{f}$ & axial stress concentration factor for bending loading \\
\hline$T$ & tension loading \\
\hline$M$ & bending loading \\
\hline$Q$ & resultant of the normal contact pressure at the shoulder \\
\hline$F_{i}$ & resultant of the normal contact pressure at the thread $i$ \\
\hline
\end{tabular}

\section{Introduction}

Stress concentrations in structures submitted to cyclic loading are frequently the sites of crack initiation. In particular structures presenting notches, such as tubes or threaded assemblies, exhibit a strong risk of high cycle fatigue. For the oil and gas industry Hill et al. [1] reported that $65 \%$ of the drillstring failures can directly be related to fatigue phenomena. One can trace the history and the interest in this domain with a finite element analysis of the connection [2] and the recent presentation of real size fatigue rig [3]. Although a series of recent works have focused on fatigue of notched specimen $[4,5,6]$ or on the stress distribution in connections $[7,8,9]$, the complete problem of the lifetime prediction procedure ranging from the determination of loading to the prediction of fatigue life has not been a definitive answer so far. 
The fatigue design methodology for structures can generally be separated into two different steps: a mechanical analysis and a fatigue analysis. The mechanical analysis is performed in order to compute the stabilized cycle of the multiaxial stress field $\underline{\underline{\underline{\Sigma}}}$, i.e. the elastic or plastic shakedown state of the structure. This analysis can take into account the cyclic plasticity encountered in the stress concentration zones and can be performed with different tools such as finite elements method [10,11] or analytical and semi-analytical solutions [12,13,14].

The fatigue analysis is then performed to compute the number of cycles before failure, denoted as a macroscopic crack initiation. Depending of the elastic or the plastic shakedown state of the structure, different damage states will occur and appropiate criteria can be applied. Let us cite as examples the the energetic approach $[15,16]$ for Low Cycle Fatigue (LCF) or the critical plane approach $[18,19,20,17]$ for High Cycle Fatigue (HCF). It is important to mention that most of these fatigue criteria are not suitable for structures presenting high stress gradients, since they are based on a fatigue reference curve on smooth specimen. This problem has been tackled using approaches available for engineers which takes into account the notch effect such as the critical distance or volume approaches [21,22,23,24,25,26].

The present work is to present a global design methodology. The study presented here will focus on the computation of the stress field induced in the threaded connection and the application of both the Dang Van fatigue criterion [17]. A similar work has been already presented in [27] which focuses on fatigue lifetime of bolt with the application of the Dang Van criterion. The present approach is based on smooth specimens rather than directly on the bolts. The novelty with respect to bolts is the introduction of the prestress due to the make up torque. The step by step methodology permits to include further effects in the fatigue computation like the notch effect, a gradient effect, etc. as presented in the preceding paragraph and also to adapt the procedure to similar structures or different materials.

We discuss two different methods for the computation of the shakedown cycle under cyclic loadings: one based on the finite element method in the elastoplastic regime and one based on the closed-form solution [28,29] in the elastic regime. The Dang Van fatigue criterion initially defined in infinite life domain are extended to finite lifetime based on simple considerations. Finally fatigue tests on small scale threaded connection are performed to assess the accuracy the fatigue methodology presented here.

\section{The studied structure}

The present a lifetime prediction procedure for drillstrings as employed in the oil and gas industry, which is a threaded assembly of tubes as illustrated in Fig. 1. The drillstrings have a length of several kilometers and a diameter of the order of 
ten to thirty centimeters. The roots of the threaded assemblies are characterized by a radius of some millimeters. One can easily remark that the global problem of fatigue of this drillstring encompasses several length scales:

- the scale of the drillstring associated with a rod model in order to represent the complete dynamics of the drillstring considering the control and cutting problems. The main variables are here the generalized stresses in the rod: the tension $T$, the torsion $C$ and the bending moment $M$, which are functions of the curvilinear coordinate along the drillstring.

- the scale of the tool-joint associated to a model where the contact and the plasticity occurring in the connection are taken into consideration. The macroscopic stress field is the main parameter at this scale.

- the scale of the grain of metal associated to the mesoscopic stress field, where the macro-meso passage may be provided for example by the Dang Van fatigue criterion.

The present work will only address the last two scales. The determination of the generalized stresses at the scale of the drillstring is in itself which can solved using so-called torque and drag models [30]. The following discussion will focus only on the tool-joint because it has been reported that this is the preferential site of crack initiation in drillstring [31].

Determining the macroscopic stress field induced by the cyclic loading on the components of the drillstring based on the generalized stresses may be very complicated without Finite Element Method. For components presenting geometries such as sharp or blunt V-notches, the computations can be dealt with analytical tools $[12,13,14]$. Nevertheless, the difficulty arises when the component is a threaded assembly. Indeed, one has to take into account not only the complex geometry of the threads but also the contact between the pin and the box, i.e. the male and female parts of the assembly, as well as the plasticity induced by stress concentrations.

It is important to notice that the stresses at the scale of the connection are determined both by the global loads and the Make-Up torque $C_{u p}$. The Make-Up torque represents the tightening torque applied on the connection which ensures a good fit between the male and female pieces. Its roles are the transmission of the torque to the drillbit and sealing of the inner tube and avoid leakage of the drilling mud. We will further remark that it plays an important role on the fatigue life of the connection.

\section{Mechanical analysis}

The main results presented in this section are based on a closed-form solution dedicated to the estimations of the stress field at particular points of a threaded con- 
nection. However some parameters of this solution can only be determined from results of finite element computations of a threaded connection; stress localizations and the contact between the two parts of the assembly, i.e. pin and box, allowing the modelling of the influence of the Make-Up torque on the stress field.

The presentation starts with a complete finite element analysis of the threaded assembly and ends with the closed-form solution.

\subsection{Finite Element computations}

The finite element model of the threaded assembly has been developed in the commercial code Abaqus[32]. Two kinds of models have been used: (i) an axisymmetric one for the case of tension and compression loading $T$ and (ii) a $3 \mathrm{D}$ model for the case of bending loading $M$. The axi-symmetric model is composed of about 42000 elements including 1900 for the contact and the 3D model has 58000 elements which 6100 are devoted for the contact. The computing time ratio was 1:10 between the two models. Both models neglect the helix angle of the threads, which is a reasonable assumption, as for instance explained in [50]. Alternative solutions involving 2D harmonic models could also have been used to deal with bending loading and would have diminished the computational time. The mechanical cyclic behavior of the steel $4145 \mathrm{H}$ (or steel 42 CrMo4) constituting the tool-joint has been modeled with an elastoplastic law with a linear kinematic hardening:

$$
\underline{\underline{\dot{\alpha}}}=\frac{H}{\sigma_{Y}}(\underline{\underline{\sigma}}-\underline{\underline{\alpha}}) \dot{\varepsilon}_{p}^{e q}
$$

where $\sigma_{Y}$ is the yield limit, $\underline{\underline{\alpha}}$ is the residual plastic stress field, $H$ is the kinematic hardening modulus and $\dot{\varepsilon}_{p}^{e q}$ is the equivalent plastic strain rate. This type of behavior has shown good agreement with respect to uniaxial cyclic tension test [28]. Without discussing the complete solution at this point, let us simply remark that after five cycles the structure reached an elastic shakedown state. This information will show up to be essential for the application of the fatigue criteria.

The Make-Up torque has been simulated by overlapping the pin and the box at the level of the shoulder in the beginning of the computation. The contact algorithm will determine contact pressures to reduce the overlapping gap to zero. The Make-Up torque is deduced from the contact pressures and the measured friction coefficient $\mathrm{f}=0.1$. This type of connection models have been used previously and its accuracy with respect to experimental measurements has been assessed in [11,7], and also more recently for steel/aluminum connections in [51]. The reported friction coefficient varied between 0.08 for steel structures in [11] to $0.13--0.39$ for steel-aluminum structures in [51]. 
The finite element computation have shown that the maximum stress field is always located either at the root of the Last Engaged Thread of the pin (LET) or at the root of the First Engaged Thread of the box (FET), as shown in Fig. 2, for tension and bending loadings, which matches results from the literature [33,9,34].

\subsection{Closed-form solutions}

Although the FEM computations are useful for the precise representation of real geometry of the connection as well as the non linearities introduced by the contact and the plasticity, they are time consuming. Therefore, for the purpose of a fatigue analysis, we propose an semi-analytical solution devoted to the computation of the local stress field with the use of an equivalent mechanical model.

Recently, a set of closed-form solution devoted to the computation of the elastic stress field for a tube presenting an internal or an external circumferential notch has been proposed in the companion paper [29]. In this section, we develop an adaptation of this solution to determine locally the stress field within a threaded connection.

The solution presented in [29] shows some limitations with respect to the dimensions of the notched tube. In this purpose, we studied the validity of the closed-form solution for various geometrical tubes regarding to a parameter $\xi$ characterizing the notched tube geometry. The results show that the solution is applicable if the parameter $\xi$ is below a critical value $\xi^{*}$ contained in the interval $[0.21,0.27]$. Concerning threaded connections used in oil and gas industry, the parameter $\xi$ is ranging from 0.1 to 0.19 which allows us to use the closed-form solution for notched tube.

Since only the stresses at the roots of the thread are considered for the fatigue analysis, one can say that this stress field is principally driven by the axial stress concentration factor $K_{Z Z}$, which gives the ratio between the maximum local axial stress and the applied gross axial stress. It seems then reasonable to perform a mechanical equivalence between the local stress field at the root of the LET or FET of the connection and the local stress field at the root of an external or internal notched tube as it is illustrated in Fig. 3.

For tension loading, the only forces driving the stress field at the root of the LET are the tension loading $T$, the resultant of the normal contact pressure at the shoulder $Q$ and the resultant $F_{1}$ of the normal contact pressure at the LET (see Fig. 3). Thus, the only forces driving the stress field at the root of the FET are the tension loading $T$ and the resultant $F_{n}$ of the normal contact pressure at the FET , $n$ being the number of thread sections of the tool-joint.

Therefore, invoking the balance of forces on adequate subparts of the pin and the box, one can write the following equations 


$$
\begin{array}{ll}
T+Q+F_{1}=\int_{R i}^{R_{o}} \Sigma_{Z Z}(R) 2 \pi R d R & \text { for the LET } \\
T+F_{n}=\int_{R_{o}}^{R_{e}} \Sigma_{Z Z}(R) 2 \pi R d R & \text { for the FET. }
\end{array}
$$

where $R_{i}, R_{e}$ and $R_{o}$ are respectively the internal radius, the external radius and the notch tip distance of the tube at the level of the considered thread, as illustrated in Fig. 3. For instance, equation (2) can be obtained by expressing the axial equilibrium of the lower part of the male part, up to the first engaged thread. In order to solve those equations, one will need the expressions of the resultants $Q, F_{1}$ and $F_{n}$ as a function of the applied loadings. This task has been performed by investigating the influence of the Make-Up torque $C_{u p}$ on the contact pressures under tension loading with the help of the numerical model presented before.

The first result of this study deals with the resultant of the normal contact pressure at the shoulder $Q$. As depicted in Fig. 4, the dependence of the resultant $Q$ with the Make-Up torque $C_{u p}$ approximately follows a bilinear law

$$
Q=\left\{\begin{array}{cc}
Q_{u p}\left(1-\frac{\Sigma_{o}}{\Sigma_{u p}}\right) & \Sigma_{o}<\Sigma_{u p} \\
0 & \Sigma_{o}>\Sigma_{u p}
\end{array}\right.
$$

where $\Sigma_{u p}$ is the tensile stress for which the contact is completely lost at the shoulder, $Q_{u p}$ is the resultant of the normal contact pressure at the shoulder induced only by the Make-Up torque $C_{u p}$ and $\Sigma_{o}$ is the applied uniform stress given by:

$$
\Sigma_{o}=\frac{T}{S_{T J}}
$$

with

$$
S_{T J}=\pi\left(R_{E}^{2}-R_{I}^{2}\right)
$$

and where $R_{E}$ and $R_{I}$ are respectively the external and internal radius of the tool joint (see Fig. 3).

A good estimation of the parameters $Q_{u p}$ and $\Sigma_{u p}$ is obtained by the following formula: 


$$
\begin{aligned}
& Q_{u p}=\frac{C_{u p}}{\mathrm{f} R_{u p}}, \\
& \Sigma_{u p}=\frac{Q_{u p}}{S_{u p}}
\end{aligned}
$$

where the radius $R_{u p}$ represents the mean radius of the pin along the threads of the connection (see Fig. 3), the parameter $\mathrm{f}$ is the friction coefficient and the area $S_{u p}$ is the cross sectional area of the tube and is equal to

$$
S_{u p}=\pi\left(R_{e}^{2}-R_{i}^{2}\right)
$$

The approximation (7) has been formulated without the influence of the thread helix and is obtained by computing the torque due to the resultant acting at the shoulder and the resultant of all forces acting on the threads. For a more complete formulation, the reader can refer to $[35,11]$.

The second result refers to the resultants of the normal contact pressures on the flank of the threads $F_{i}$ which has already been studied in $[35,11]$ without the influence of the Make-Up torque.

The Fig. 5 shows for traction loading the distribution of the dimensionless resultants $\mathcal{F}_{i}$ along the threads given by

$$
\begin{aligned}
& \mathcal{F}_{i}=\frac{F_{u p}^{i}}{T}\left(\frac{F^{i}}{F_{u p}^{i}}-\frac{Q}{Q_{u p}}\right), \\
& \mathcal{F}_{i}^{u p}=\frac{F_{u p}^{i}}{Q_{u p}}
\end{aligned}
$$

where $F_{u p}^{i}$ is the resultant of the normal contact pressure on the flank of the threads due to the Make-Up torque only.

One can notice that this distribution is almost independent on the Make-Up torque value. It has been also verified that it is independent of the tensile load and that the contact conditions do not change. This means that the distribution of the forces is a purely geometric characteristic of the connection. The loads acting on the threads for any traction loading $T$ and Make-Up torque $C_{u p}$ values are computed using the dimensionless parameters $\mathcal{F}_{i}$ based on single load.

Inserting the axial stress component $\Sigma_{Z Z}$ and the resultants of the contact pressure $Q$ and $F_{1}$ into (2) and introducing the axial stress concentration factor $K_{Z Z}^{t}$ leads to 
the expression of the axial stress $\Sigma_{Z Z}^{\max }$ at the root of the LET of the pin for traction loading

$$
\Sigma_{Z Z}^{\max }=\left\{\begin{array}{cc}
K_{Z Z}^{t}\left[\frac{S_{T J}}{S_{u p}}\left(1+\mathcal{F}_{1}\right)-1-\mathcal{F}_{1}^{u p}\right] \Sigma_{o}+K_{Z Z}^{t} \Sigma_{u p}\left(1+\mathcal{F}_{1}^{u p}\right) & \Sigma_{o}<\Sigma_{u p} \\
K_{Z Z}^{t}\left[1+\mathcal{F}_{1}\right] \frac{S_{T J}}{S_{u p}} \Sigma_{o} & \Sigma_{o}>\Sigma_{u p}
\end{array}\right.
$$

where $K_{Z Z}^{t}$ is the axial stress concentration factor due to tension loading and its expression is given in [29].

And similarly inserting the axial stress component $\Sigma_{Z Z}$ and the resultants of the contact pressure $Q$ and $F_{n}$ into (3) leads to the expression of the axial stress $\Sigma_{Z Z}$ at the root of the FET of the box for traction loading

$$
\Sigma_{Z Z}^{\max }=\left\{\begin{array}{cc}
K_{Z Z}^{t}\left[\frac{S_{T J}}{S_{u p}}\left(1+\mathcal{F}_{n}\right)-\mathcal{F}_{1}^{u p}\right] \Sigma_{o}+K_{Z Z}^{t} \Sigma_{u p} \mathcal{F}_{n}^{u p} & \Sigma_{o}<\Sigma_{u p} \\
K_{Z Z}^{t}\left[1+\mathcal{F}_{n}\right] \frac{S_{T J}}{S_{u p}} \Sigma_{o} & \Sigma_{o}>\Sigma_{u p}
\end{array}\right.
$$

For bending loading, the stress field at the roots of the LET of the pin and the FET of the box is induced by the bending loading $M$ and the loading due to the contact as $Q$ and $F_{1}$ for the LET and $F_{n}$ for the FET. The part of the stress field induced by the bending loading is explicitly given in [29] and the part of the stress field induced by the resultants of the contact pressures is obtained by performing an analogy between the bending loading and the traction loading. This analogy is obtained by determining an equivalent traction loading $\Sigma_{o}^{*}$ from a bending loading $M$ given by

$$
\Sigma_{o}^{*}=\frac{M R_{E}}{I_{T J}}
$$

with $I_{T J}$ being equal to

$$
I_{T J}=\frac{\pi}{4}\left(R_{E}^{4}-R_{I}^{4}\right)
$$

This axial stress $\Sigma_{o}^{*}$ represents simply the maximal axial stress induced by the flexural moment $M$ at the outer fiber of the tube. 
Therefore by invoking the global equilibrium conditions, we obtain the following equations

$$
\begin{array}{ll}
Q+F_{1}=\int_{R i}^{R_{o}} \Sigma_{Z Z}(R) 2 \pi R d R & \text { for the LET }, \\
F_{n}=\int_{R_{o}}^{R_{e}} \Sigma_{Z Z}(R) 2 \pi R d R & \text { for the FET }
\end{array}
$$

and

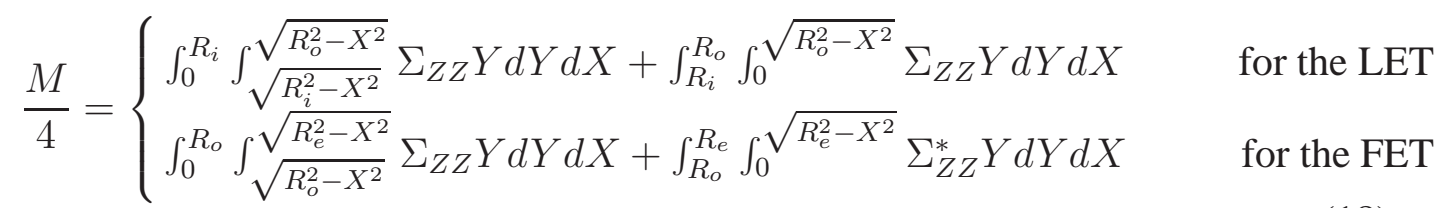

where $\Sigma_{Z Z}^{*}$ is the axial stress component induced by the bending loading on a tube without a notch .Its expression is

$$
\Sigma_{Z Z}^{*}=\frac{M R_{e}}{I}
$$

with

$$
I=\frac{\pi}{4}\left(R_{e}^{4}-R_{i}^{4}\right)
$$

Inserting the axial stress component $\Sigma_{Z Z}$ and the resultants of the contact pressure $Q$ and $F_{1}$ into (16) and introducing the axial stress concentration factors $K_{Z Z}^{t}$ and $K_{Z Z}^{f}$, respectively for traction and bending loading, leads to the expression of the axial stress $\Sigma_{Z Z}^{\max }$ at the root of the LET of the pin for bending loading

$$
\Sigma_{Z Z}^{\max }=\left\{\begin{array}{cc}
K_{Z Z}^{t}\left[\Gamma+\frac{S_{T J}}{S_{u p}} \mathcal{F}_{1}-1-\mathcal{F}_{1}^{u p}\right] \Sigma_{o}^{*}+K_{Z Z}^{t} \Sigma_{u p}\left(1+\mathcal{F}_{1}^{u p}\right) & \Sigma_{o}^{*}<\Sigma_{u p} \\
K_{Z Z}^{t}\left[\Gamma+\frac{S_{T J}}{S_{u p}} \mathcal{F}_{1}\right] \Sigma_{o}^{*} & \Sigma_{o}^{*}>\Sigma_{u p}
\end{array}\right.
$$

with

$$
\Gamma=\frac{K_{Z Z}^{f}}{K_{Z Z}^{t}} \frac{R_{e} I_{T J}}{R_{E} I} .
$$


And similarly inserting the axial stress component $\Sigma_{Z Z}$ and the resultants of the contact pressure $Q$ and $F_{n}$ into (17) leads to the expression of the axial stress $\Sigma_{Z Z}^{\max }$ at the root of the FET of the box for bending loading

$$
\Sigma_{Z Z}^{\max }=\left\{\begin{array}{cc}
K_{Z Z}^{t}\left[\Gamma+\frac{S_{T J}}{S_{u p}} \mathcal{F}_{n}-\mathcal{F}_{n}^{u p}\right] \Sigma_{o}^{*}+K_{Z Z}^{t} \Sigma_{u p} \mathcal{F}_{n}^{u p} & \Sigma_{o}^{*}<\Sigma_{u p} \\
K_{Z Z}^{t}\left[\Gamma+\frac{S_{T J}}{S_{u p}} \mathcal{F}_{n}\right] \Sigma_{o}^{*} & \Sigma_{o}^{*}>\Sigma_{u p}
\end{array}\right.
$$

The Fig. 6 shows the comparison between the closed-form solution and the FEM results for tension loading along the bisector of the notch at the LET of the pin. This solution being based on the use of complex elasticity, it can provide accurate solutions for the multiaxial stress in axysymmetric situations. One can then note that the closed-form solution gives good results in the neighborhood of the notch with an error less than $1.5 \%$ for the axial component $\Sigma_{Z Z}$ and the radial component $\Sigma_{R R}$ and less than $8 \%$ for the circumferential component $\Sigma_{\Theta \Theta}$. However the solution becomes less accurate when we go far away from the notch particularly for the radial stress component $\Sigma_{R R}$.

The Fig. 7 shows the comparison of the closed-form solution and the FEM results for the axial and the circumferential stress components at the level of the root of the LET of the pin for various Make-Up torque $C_{u p}$ and tension loading $\Sigma_{o}$. One can note that the proposed solution shows good agreements with respect to FEM results, for all loading cases.

\section{Fatigue analysis}

In this part, we are interested in the application of a fatigue criterion dedicated to the predictions of the life time of threaded assemblies. Once the stabilized cycle of the macroscopic strain and stress field is determined, a post-treatment will provide the critical points and the fatigue life $N$, i.e. number of cycles to failure, of the structure. The used fatigue criterion is the Dang Van criterion [18].

The criterion of Dang Van, in its initial formulation, allows to define the limit of the imposed external loads under which the structure will have an infinite life. A passage between the macroscopic scale of the components and the mesoscopic scale of the grain allows to state that the lifetime is infinite if the mesoscopic shear stress $\tau(t)$ and the hydrostatic pressure $P(t)$ satisfy the following inequality

$$
\max \left\{\tau(t)+a_{\infty} P(t)\right\} \leq b_{\infty}
$$


where the coefficients $a_{\infty}$ and $b_{\infty}$ are defined as

$$
a_{\infty}=\frac{t_{\infty}-f_{\infty} / 2}{f_{\infty} / 3} \quad b_{\infty}=t_{\infty}
$$

These coefficients are deduced from two Woehler curves from plain smooth specimens giving the fatigue limit $t_{\infty}$ in alternated torsion and $f_{\infty}$ in fully reversed bending. In general, the Woehler curves are not defined for an infinity of cycles but rather for $10^{7}$ to $10^{6}$ cycles. We recall that the inequality (24) has to be verified for all points of the structure.

In order to obtain a criterion suitable for the High Cycle Fatigue regime, some modifications must be done as presented also in [27]. Let us assume that we have a complete series of torsion and bending Woehler curves for the material under discussion. For each finite number of cycles $N$ we can define from the preceding Woehler curves the limit amplitude in torsion and bending, denoted $t_{N}$ and respectively $f_{N}$, which will conduct to a lifetime of exactly $N$ cycles. Each of these pairs $\left(t_{N}, f_{N}\right)$ defines a corresponding pair of coefficients

$$
a_{N}=\frac{t_{N}-f_{N} / 2}{f_{N} / 3} \quad b_{N}=t_{N}
$$

of a new line in the Dang Van plot representing the stress path in the mesoscopic shear-pressure coordinates.

Thus the structure will have a lifetime of at least $N$ cycles if

$$
\max \left\{\tau(t)+a_{N} P(t)\right\} \leq b_{N}
$$

The different lines obtained form then a bundle in the Dang Van plot, which will be cut by the stress path in this space (see Fig. 8). The number of cycles to failure is defined by the tangent to the shear-pressure path.

From a physical point of view, the fatigue life defined before by the number of cycles to failure $N$ corresponds to the nucleation of a small macroscopic crack in High Cycle Fatigue regime. The initiation phase is the critical phase from the point of view of design, since once the crack has initiated it is not likely to arrest. Moreover, the present experimental observations of failure of the specimen tested showed that the propagation phase of the macroscopic crack can be neglected when compared to the initiation phase. Indeed macroscopic crack initiation was attained for $\approx 10^{5}$ and complete failure of the specimen at only $\approx 300$ cycles after; similar observations are reported in [36]. However if more precision is needed for the lifetime prediction, one should use for instance the LEFM approach coupled with 
the Paris law in order to determine the remaining lifetime from macroscopic crack initiation to complete failure.

For the sake of simplicity, we consider here as a first approximation that the Dang Van lines are all parallel. This implies that:

$$
a_{N} \approx a_{\infty}
$$

In order to link the equivalent mesoscopic shear stress $b_{N}$ to the fatigue life $N$, we introduce a fitting law to describe the Wöhler curve in alternated torsion proposed by [37]

$$
t_{N}=\delta N^{-\lambda}+t_{\infty}
$$

where $\lambda$ and $\delta$ are the fitting parameters. In the case where we have at one's disposal only a Wöhler curve in fully-reversed bending, the relation (26) allows us to compute the Wöhler curve in alternated torsion. This hypothesis is very strong but due to the lack of experimental data on our material, this computation can be seen as a first approximation of lifetime predictions.

A comparison between the closed-form solution and the FEM results on the application of the Dang Van criterion is depicted in Fig. 9. This figure shows the computation by the two methods, analytical and numerical, of the equivalent mesoscopic shear stress $\tau+a_{\infty} P$ introduced in (27). This type of presentation has been chosen for relevant comparisons since, in the HCF domain, a small error on the stresses leads to much higher error on the fatigue life. As it is depicted, the closedform solution gives reasonable predictions with an error of $10 \%$ when predicting at the root of the LET of the pin and with an error smaller than $20 \%$ when predicting at the root of the FET of the box.

\section{Results and Discussions}

In order to validate the proposed fatigue life criterion, fatigue test in repeated tension has been performed on a small scale threaded connection with a machine test INSTRON with a maximum loading equal to $250 \mathrm{kN}$.

A small scale threaded connection has been designed by downscaling of an API connection with the same the stress concentration factor. This connection has been designed to test the methodology presented here and should not be understood as a downsized experiment for the real connection. Moreover the dimensions of the small scale connection where chosen to be such that, with the available machine 
test, it was possible to perform fatigue test in the complete range of the finite lifetime domain, i.e. $10^{5}$ to $10^{7}$ cycles. It is well known that the scale change is likely to induce a change in the fatigue process due to the size effect $[43,22,23]$. However, due to pratical constraints, i.e. the maximum load of the available machine, we were obliged to downsize the geometry including the notch root radius.

Papadopoulos showed that the gradient effect is more important than the size effect [38] which strengthens our choice.

The small scale threaded connection corresponds to a $1 / 4$ downsizing of the NC46 API connection. It has an internal $R_{I}$ and an external $R_{E}$ radii respectively equal to $10.4 \mathrm{~mm}$ and $20 \mathrm{~mm}$ and the geometry of the threads presents an opening angle equal to $55^{\circ}$, a root radius equal to $0.25 \mathrm{~mm}$ and the distance of the notch tip of the LET from the longitudinal axis of the connection $R_{o}$ is equal to $15 \mathrm{~mm}$. As a comparison, the root radius of the initial full scale threaded connection is equal to 1. $\mathrm{mm}$. The theoretical stress concentration factor $K_{t}$ provided by the finite element computations is equal to 5.57 for tension loading. More details of the geometry of the used connection can be found in [28].

The small scale threaded connection is equally made of a $42 \mathrm{CrMo} 4$ steel as the API connections.

The Tab. 1 presents the values of the mechanical properties obtained on a straincontrolled cyclic tensile test at $\pm 2 \%$ of elastoplastic deformation for the elastoplastic parameters, the values of the Dang Van fatigue parameters for fatigue limits on smooth specimen $t_{\infty}=260 \mathrm{MPa}$ and $f_{\infty}=400 \mathrm{MPa}$ [39] and the parameters $\delta$ and $\lambda$ introduced in (29) obtained from a fully reversed bending fatigue test on smooth specimen [40] and the use of the simplification (28).

Table 1

The macroscopic material parameters: $E$ Young modulus, $\nu$ Poisson ratio, $\sigma_{Y}$ yield limit, $H$ kinematic hardening modulus and $a_{\infty}, b_{\infty}$ Dang Van fatigue parameters.

\begin{tabular}{|c|c|c|c|c|c|c|c|}
\hline$E \quad[\mathrm{GPa}]$ & $\nu$ & $\sigma_{Y}[\mathrm{MPa}]$ & $H \quad[\mathrm{MPa}]$ & $a_{\infty}$ & $b_{\infty} \quad[\mathrm{MPa}]$ & $\lambda$ & $\delta$ \\
\hline 210 & 0.3 & 835 & 8333 & 0.45 & 260 & 0.15 & 678 \\
\hline
\end{tabular}

The fatigue tests starts with imposing the Make-Up torque $C_{u p}$ of $133 \mathrm{Nm}$ or $433 \mathrm{Nm}$ and continous with a cyclic repeated tensile loading $T_{\max }\left(R=\frac{T_{\min }}{T_{\max }}=\right.$ $0)$. This make-up torque was applied though dead weights that provided an obviously repeatable torque value on the specimen. For the higher torque, the tension fatigue test has been duplicated in order to quantify the scatter of the fatigue life results.

The results of the repeated tension fatigue test are shown in Tabs. 2 and 3. The experimental scatter of the fatigue life has a maximum value equal to $21 \%$. The 
loads applied in this study induced local plasticity at the root of the threads of the connection. Finite element results show that the equivalent plastic strain $\varepsilon_{p}^{e q}$ at the LET has a mean value over all the tests equal to $1.6 \%$ and $0.31 \%$ for $C_{u p}$ equal to $433 \mathrm{Nm}$ and $133 \mathrm{Nm}$ respectively.

Table 2

Results of the fatigue tests for a Make-Up torque equal to $433 \mathrm{Nm}$.

\begin{tabular}{|c|c||c|c|c|c|c|}
\hline \multicolumn{2}{|c|}{$T_{\max }[k N]$} & 138 & 120 & 113 & 100 & 88 \\
\hline \hline \multirow{2}{*}{$\begin{array}{c}N \\
{[\text { cycles }]}\end{array}$} & test 1 & 113677 & 271328 & 454372 & 718460 & 1516831 \\
\cline { 2 - 7 } & test 2 & 90066 & 258030 & 409882 & 855261 & 1759682 \\
\hline
\end{tabular}

Table 3

Results of the fatigue tests for a Make-Up torque equal to $133 \mathrm{Nm}$.

\begin{tabular}{|c||c|c|c|c|}
\hline$T_{\max }[k N]$ & 105 & 97 & 94 & 88 \\
\hline \hline$N[$ cycles $]$ & 91492 & 199827 & 981140 & 1801615 \\
\hline
\end{tabular}

The Fig. 11 shows the crack initiation site which takes place at the root of the LET of the pin of the threaded connection. The prediction of the crack initiation site made with the Dang Van criterion is in good agreement with the experimental results.

The distribution of the stress components along the bisector of the root of the LET is presented in Fig. 12 for a Make-Up torque equal to $433 \mathrm{Nm}$ and a repeated tension loading equal to $113 \mathrm{kN}$. This result is obtained by a fully elastoplastic finite element computation after five cycles of repeated tension loading which was enough to obtain elastic shakedown. The load induces plasticity at the root of the LET and therefore the maximum stresses take place at a distance equal to $0.16 \mathrm{~mm}$ from the tip of the root of the LET.

The Figure 13 shows the mesoscopic shear stress and hydrostatic pressure, evaluated along the bisector of the root of the LET. One can notice that the maximum values of the equivalent mesoscopic shear stress $\tau+a_{\infty} P$ and of the stress components are reached at the same location. The difference between the value of the equivalent mesoscopic shear stress at the tip of the root of the LET and at the distance equal to $0.16 \mathrm{~mm}$ is equal to $15 \mathrm{MPa}$ which is less than $4 \%$ of the value at the tip of the root of the LET. The predictions of the fatigue lives at this two particular points leads to a reduction of the number of cycles equal to $50 \%$. This result highlights the difficulty to estimate the fatigue life of structures in the High Cycle Fatigue domain.

The direct application of the modified Dang Van fatigue lifetime criterion (27) is then illustrated in Fig. 14, where stresses where computed at the root of the LET of the pin. One can see that the Dang Van criterion gives too conservative predictions 
with a mean ratio between the experimental fatigue lives and the predictions of about 15 for both values of the Make-Up torque. Note that evaluating the criterion at its most critical value from a fatigue point of view (i.e not at the root of the LET but at a given distance from it) would further increase the discrepancy between the prediction and the test results. It would indeed predict even smaller fatigue lives than those presented in Fig. 14.

Let us discuss now the possible reasons for such a discrepancy.

A first explanation is related to fatigue criterion itself. The obtained stress state has a high hydrostatic component, as can be observed on Fig. 12. In this region, we have no precise indication that the original infinite lifetime criterion is still valid. This phenomenon is also emphasized by the fact that the experience used for the identification of the parameters of the criterion are done in low hydrostatic pressure region, which may induce a lack of precision in the region of interest. Furthermore, a strong assumption made in the present approach is the hypothesis of parallelism of the lines defining the structure lifetime, which is presented in (28). It is clear that replacing the $a_{\infty}$ coefficient with a cycle dependent coefficient $a_{N}$ could improve the prediction in this domain. Further improvements can be obtained based on recent evolutions of the Dang Van criterion [41] in the high hydrostatic stress region.

A second kind of explanation for the discrepancy lies in the already mentionned size effect which is well known for geometric discontinuities such as notches or welds. Indeed, these types of geometric discontinuities induce a stress-gradient effect [42] as well as a scale effect $[43,44]$ which leads to a reduction of the fatigue limit of the material. Therefore applying a classical fatigue criterion on structures presenting a geometric discontinuity will generally underestimate the fatigue lives as showed in Fig. 14 with the Dang Van criterion.

Recently, a study of the effect of the stress-gradient on fatigue has been performed in $[45,46]$ using the Dang Van criterion. Based on a numerical model of crystal plasticity it is shown that, in the presence of a notch, only few grains in the neighborhood of the notch tip are highly stressed. Therefore the likelihood that a grain be oriented in such a way that its preferential slip system coincides with the orientation of the maximum principal stresses is very small. This kind of consideration provides an explanation to the fact that the use of a classical fatigue criterion on such structures provides very conservative lifetimes, as can be seen on our example. Unfortunately such analyses are for the moment only qualitative and are not yet suitable to engineering applications.

These two forementionned phenomena, namely the nature of the fatigue criterion and stress gradient effect, provide plausible reasons for the observed conservatism of our approach. 
In order to take into account the notch effect, one could apply different stress reduction techniques like the critical point technique discussed in $[21,22,52]$ or the volumetric approach discussed in $[24,47,25,26]$. On figure 15 , we display the fatigue lifetime predictions obtained with the Dang Van criterion applied after reducing the stress field by $11 \%$. One can remark that the predictions now match the experimental observations and that this choice is coherent with the orders of magnitudes for the corrections encountered in the beforementionned papers.

\section{Conclusions}

This paper presented a methodology for fatigue lifetime predictions devoted to threaded assemblies. This technique is based on a mechanical analysis and a fatigue analysis.

The mechanical analysis provides the stabilized stress path during the cyclic loading. This can be done by two different methods:

- a complete finite element method which takes into account the complete elastoplastic material behavior, the exact geometry of the threaded assembly and the contact between the two parts of the connection in order to estimate the final elastic shakedown state at any points of the structure,

- a closed-form solution which predicts directly the elastic stress field developed at the root of the LET and FET of the connection.

The drawback of the finite element method is the large time computation which makes it not practical for real time survey of the damage during the drilling process. This is overcome by the closed-form solution which computes stresses instantaneously. For the time being this solution is purely elastic but it can be easily extended to elastoplastic behavior with the use of the Neuber rules [48] or the Zarka method [49] which have been recently employed for example in [16].

The fatigue analysis is performed using the Dang Van criteron which has been extended in the finite lifetime domain. In order to validate the fatigue methodology, experimental fatigue tests on small scale threaded connections have been performed. The results have shown that the direct application of the fatigue life criterion on the most critical location near the notch root underestimates the fatigue lives when the Dang Van criterion is used.

This may be explained firstly by the fact that this criterion probably needs to be adapted in the high hydrostatic pressure domain, in order to be applied to this type of notched structures. A second explanation is linked to a stress gradient effect, which leads to a need of correction or averaging of the evaluated stresses, before an application in fatigue criteria, such as the Dang Van criterion. 
As a final conclusion, we can state that further work is needed in order to justify on a sound theoretical basis all the assumptions and the application of classical fatigue criterion for structures presenting geometric discontinuity and large stress gradients.

\section{References}

[1] T. H. Hill. A Unified Approach to Drillstem Failure Prevention. SPE Drilling Engineering, 1992.

[2] Tafreshi, A. and Dover, W.D. Stress analysis of drillstring threaded connections using the finite element method. International Journal of Fatigue, 15(9):429-438, 1993.

[3] Bertini, L., Beghini, M., Santus, C., and Baryshnikov, A. Resonant test rigs for fatigue full scale testing of oil drill string connections. International Journal of Fatigue, 30(6):978-988, 2008.

[4] M. Ciavarella and G. Meneghetti. On fatigue limit in the presence of notches: Classical vs. recent unified formulations. Int. J. Fatigue, 26:289-298, 2004.

[5] L. Susmel and D. Taylor. Two methods for predicting the multiaxial fatigue limits of sharp notches. Fatigue Fract. Engng. Mater. Struct., 26:821-833, 2003.

[6] R. A. Naik, D. B. Lanning, T. Nicholas, and A. R. Kallmeyer. A critical plane gradient approach for the prediction of notched HCF life. Int. J. Fatigue, 27:481-492, 2005.

[7] S. Baragetti and A. Terranova. Effects of over-torque on stress relief in conical threaded connections. J. Mech. Design, Trans. ASME, 126:351-358, 2004.

[8] J. Chen and Y. Shih. A study of the helical effect on the thread connection by three dimensional finite element analysis. Nuclear Engineering and Design, 191:109-116, 1999.

[9] K. A. Macdonald and W. F. Deans. Stress analysis of drillstring threaded connections using the finite element method. Engineering Failure Analysis, 2(1):1-30, 1995.

[10] F. P. Brennan and W. D. Dover. Stress intensity factor for threaded connections. Engineering Fracture Mechanics, 50(4):545-567, 1995.

[11] S. Baragetti. Effects of taper variation on conical threaded connections load distribution. J. Mech. Design, Trans. ASME, 124:320-329, 2002.

[12] P. Lazzarin and R. Tovo. A unified approach to the evaluation of linear elastic stress field in the neighborhood of cracks and notches. Int. J. Fracture, 78:3-19, 1996.

[13] M.L. Williams. On the stress distribution at the base of a stationary crack. ASME J. Appl. Mech., 24:109-114, 1957.

[14] B. Atzori, S. Filippi, P. Lazzarin, and F. Berto. Stress distribution in notched structural components under pure bending and combined traction and bending. Fatigue Fract. Engng. Mater. Struct., 28:13-23, 2005. 
[15] A. Banvillet, T. Palin-Luc, and S. Lasserre. A volumetric energy based high cycle multiaxial fatigue criterion. Int. J. Fatigue, 25:755-769, 2003.

[16] S. Amiable, S. Chapuliot, A. Constantinescu, and A. Fissolo. A comparison of lifetime prediction methods for a thermal fatigue experiment. Int. J. Fatigue, 28:692-706, 2005.

[17] CISM courses and lecture no. 392. International Centre for Mechanical Sciences. âĂIJHighâĂŞcycle metal fatigue. From theory to applicationsâĂİ editors Dang Van and Papadopoulos, Springer, 1999.

[18] K. Dang Van. Macro-micro approach in high-cycle multiaxial fatigue. American Society for Testing and Materials, pages 120-130, 1993.

[19] W. N. Findley. A theory for the effect of mean stress on fatigue of metals under combined torsion and axial load or bending. J. Engng Industry, Trans. ASME, 81:301306, 1959.

[20] I. V. Papadopoulos. Exploring the High-Cycle Fatigue Behavior of Metals from the Mesoscopique Scale. J. of the Mechanical Behavior of Materials, 6(2):93-118, 1996.

[21] B. Atzori, P. Lazzarin, and G. Menghetti. Fracture mechanics and notch sensitivity. Fatigue Fract. Engng. Mater. Struct., 26:257-267, 2003.

[22] D. Taylor and S. Lawless. Prediction of fatigue behaviour in stress-concentrators of arbritary geometry. Engng. Fract. Mech., 53(6):929-939, 1996.

[23] G. Pluvinage. Fatigue and fracture emanating from notch; the use of the notch stress intensity factor. Nuclear Engng Design, 185:173-184, 1998.

[24] S. Bentachfine, G. Pluvinage, J. Gilbert, Z. Azari, and D. Bouami. Notch effect in low cycle fatigue. Int. J. Fatigue, 21(5):421-430, 1999.

[25] P. Lazzarin, T. Lassen, and P. Livieri. A notch stress intensity approach applied to fatigue life predictions of weded joints with different local toe geometry. Fatigue Fract. Engng. Mater. Struct., 26:49-68, 2003.

[26] P. Lazzarin and F. Berto. Some expressions for the strains energy in a finite volume surrounding the root of blunt v-notches. ijf, 153:161-185, 2005.

[27] Y. Fares, M. Chaussumier, A. Daidie, and J. Guillot. Determining the life cycle of bolts using a local approach and the dang van criterion. Fatigue Fract. Engng. Mater. Struc., 29:588-596, 2006.

[28] M. Ferjani. Intégration des phénoménes dynamiques dans l'analyse en fatigue des garnitures de forage (Phd Thesis) Ecole Polytechnique, Palaiseau, France, 2007.

[29] M. Ferjani, A. Constantinescu, and D. Averbuch. Semianalytical solutions for elastic stresses in notched tubes in print Int. J. Fatigue, 2010 (doi:10.1016/j.ijfatigue.2010.10.009).

[30] C.A. Johancsik, D.B. Friesen, and R. Dawson. Torque and drag in directional wells prediction and measurement. In Symposium on the Mechanics of Physicochemical and Electrochemical Interactions in Porous Media, New Orlean, Louisiana, 1983. SPE/IADC Drilling Conference, SPE. 
[31] P. D. Spanos, A. M. Chevallier, N. P. Politis, and M. L. Payne. Oil Well Drilling: A Vibrations Perspective. The Shock and Vibration Digest., 35(2):81-99, 2003.

[32] Abaqus. A Finite Element Commercial Software, http://ww.abaqus.com.

[33] A. Tafreshi and W.D. Dover. Stress analysis of drillstring threaded connections using the finite element method. Int. J. Fatigue, 15(5):429-438, 1993.

[34] M. J. Knight, F. P. Brennan, and W. D. Dover. Effect of residual stress on ACFM crack measuremens in drill collar threaded connections. NDT E international, 37:337-343, 2003.

[35] R. C. Juvinall and K. M. Marshek. Fundamentals of Machine Component Design. John Wiley \& Sons, New York, 1991.

[36] C. Levaillant. Approche métallographique de l'endommagement d'aciers inoxydables austenitiques sollicites en fatigue plastique ou en fluage. $\mathrm{PhD}$ thesis, Université Technologique de Compiègne, 1984.

[37] I.V. Papadopoulos. Long life fatigue under multiaxial loading. Int. J. Fatigue, 23:839849, 2001.

[38] I. V. Papadopoulos and V. P. Panoskaltsis. Gradient dependent multiaxial highcycle fatigue criterion. In Proceedings of the 4th International Conference on Biaxial/Multiaxial Fatigue, volume 1, pages 461-476, France, 1994. SF2M Ed.

[39] H. Zenner, R. Heidenreich, and I. Richter. Dauerschwingfestigkeit bei nichtsynchroner mehrachsiger beansprunchung. Z. Werkofftech., 16:101-112, 1985.

[40] C. Boller. Material Data for Cyclic Loading, Part C: High-Alloy Steels. Elsevier, 1987.

[41] Monchiet, V, Cazacu, O, Charkaluk, E, and Kondo, D. Macroscopic yield criteria for plastic anisotropic materials containing spheroidal voids. Int.J.Plasticity, 24(7):11581189, 2008.

[42] F. Morel and T. Palin-Luc. A non-local theory applied to high cycle multiaxial fatigue. Fatigue Fract. Engng. Mater. Struct., 25:649-665, 2002.

[43] N. E. Frost. Crack formation and stress concentration effects in direct stress fatigue. The engineer, 200:464-467, 1955.

[44] D.L. Du Quesnay, M.T. Yu, and T.H. Topper. An analysis of notch-size effects at the fatigue limit. J. Testing \& Mat, 16(4):375-385, July 1988.

[45] F. Hofmann, G. Bertolino, A. Constantinescu, and M. Ferjani. A multiscale discussion of fatigue and shakedown for notched structures. Theoretical and Applied Fracture Mechanics, 48(2):140-151, 2007.

[46] Hofmann, F., Bertolino, G., Constantinescu, A., and Ferjani, M. A discussion at the mesoscopic scale of the stress-gradient effects in high cycle fatigue based on the dang van criterion. Journal of the Mechanics of Materials and Structures, 4(2):293-308, 2009. 
[47] G. Qilafku and G. Pluvinage. Multiaxial fatigue criterion for notched specimens including the effective stress range, relative stress gradient, and the hydrostatic pressure. Material Science, 37(4):573-582, 2001.

[48] H. Neuber. Theory of notch stresses: Principles for exact stress calculation. Berlin, 1958. Springer-Verlag $2^{\text {nd }}$ edition. Translation of Kerbspannungslehre : Grundlagen Fuer Genaue Spannunggrechnung.

[49] J. Zarka, J. Frelat, G. Inglebert, and P. Kasmai-Navidi. A new approach in inelastic analysis of structures. Technical report, Ecole Polytechnique, 1990.

[50] A.R. Shahani and S.M.H. Sharifi Contact stress analysis and calculation of stress concentration factors at the tool joint of a drill pipe. Materials Design, 30 :3615-3621, 2009.

[51] C. Santus , L. Bertini, M. Beghini, A. Merlo, A. Baryshnikov. Torsional strength comparison between two assembling techniques for aluminium drill pipe to steel tool joint connection International Journal of Pressure Vessels and Piping, 86: 177-186, 2009.

[52] L. Susmel, D.Taylor A simplified approach to apply the theory of critical distances to notched components under torsional fatigue loading Int. J. Fatigue, 28:417âĂ ̌̌ 430, 2006.

\section{Figures}


a)

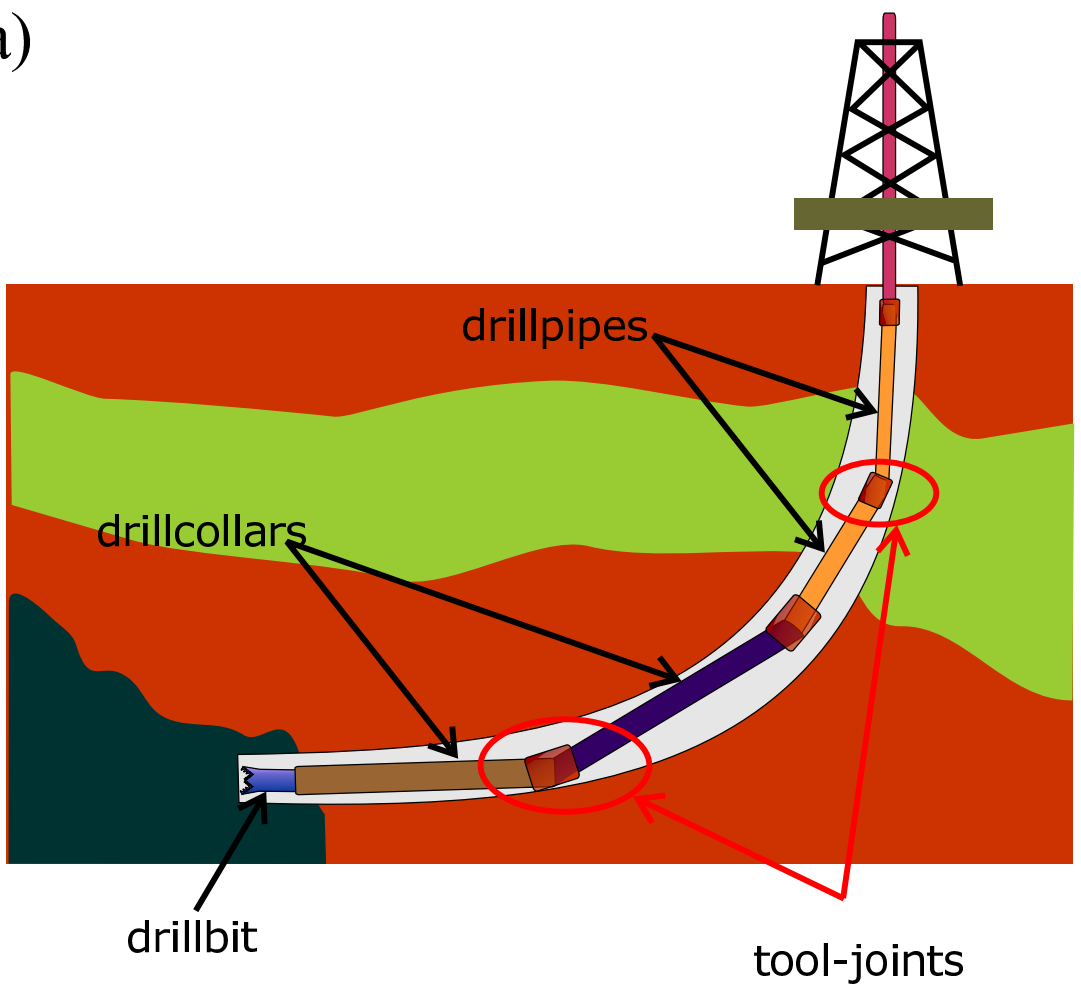

b)

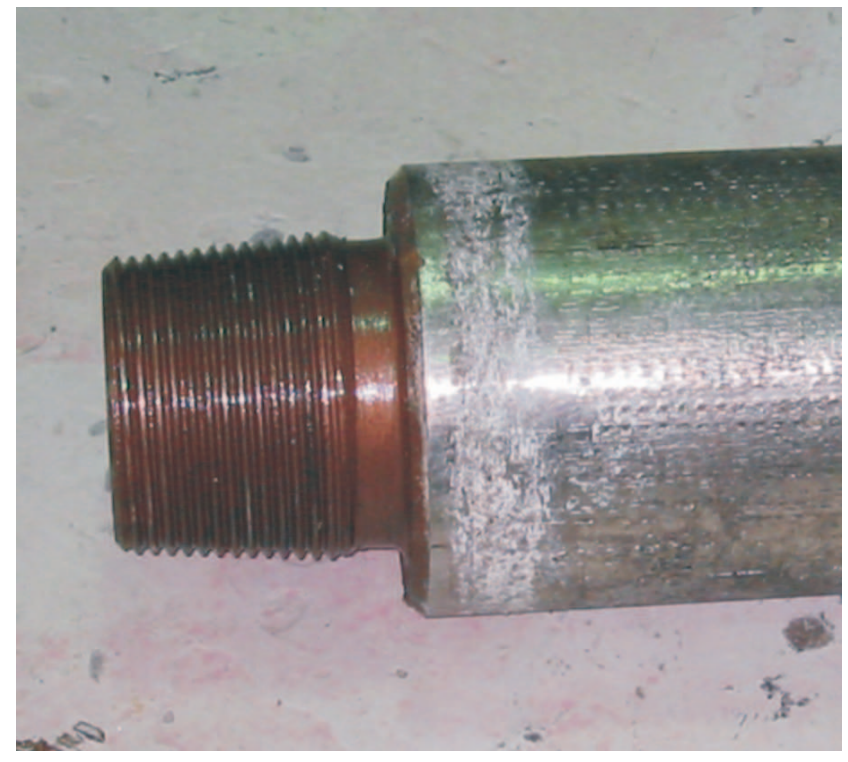

Figure 1. Description of a drillstring: a) drillstring components; b) picture of the pin part of a tool-joint. 
Figure 2. Critical points of the threaded connections: a) geometry of a threaded connection; b) root of the First Engaged Thread of the box; c) root of the Last Engaged Thread of the pin.

a)

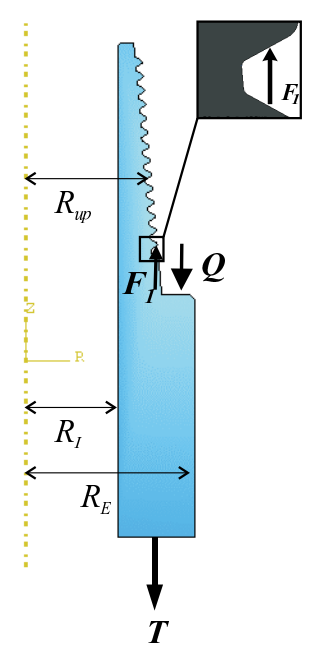

b)

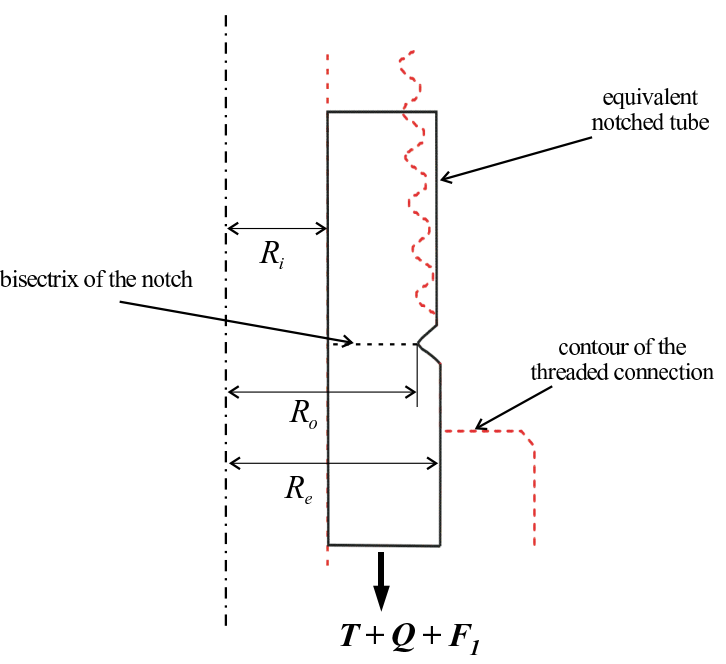

Figure 3. Mechanical equivalence at the root of the LET of the pin: a) threaded connection; b) equivalent notched tube.

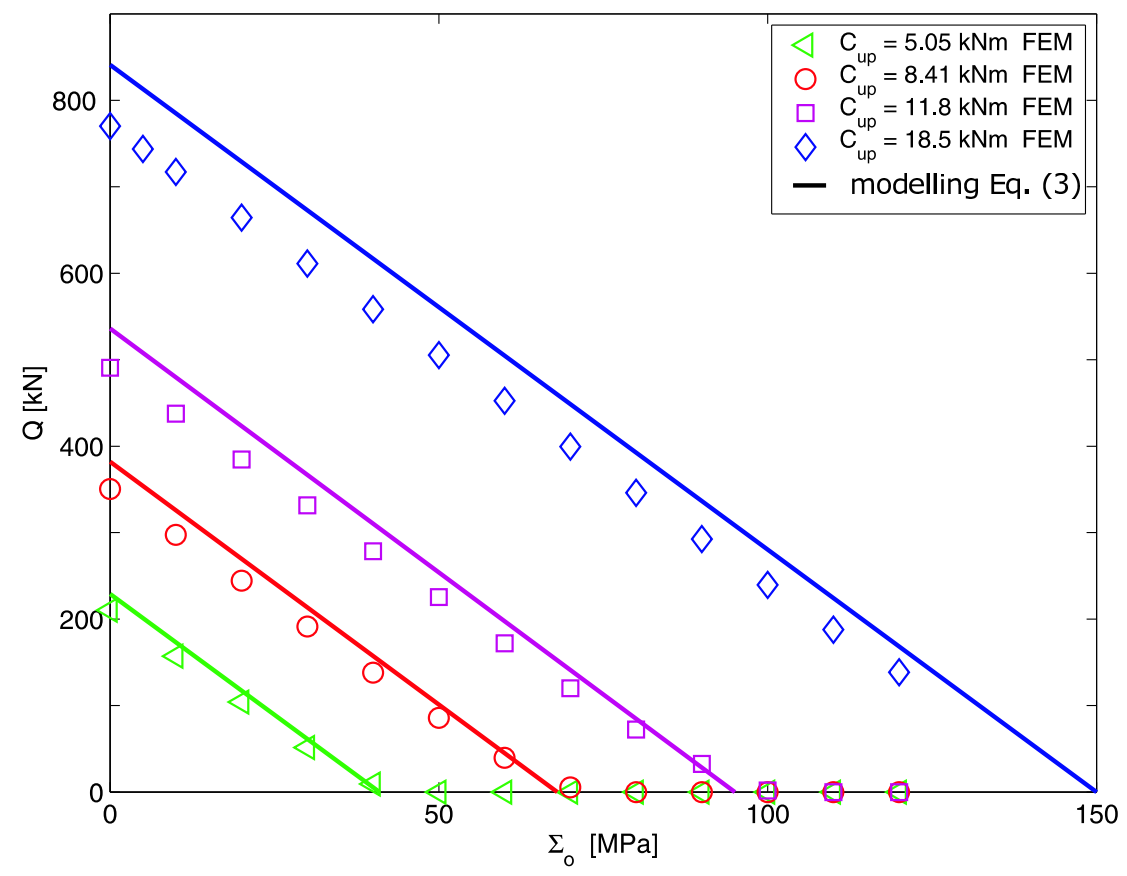

Figure 4. Resultant of the normal contact pressure at the shoulder $Q$ as a function of the applied traction loading $\Sigma_{o}$ and the Make-Up torque $C_{u p}$. 


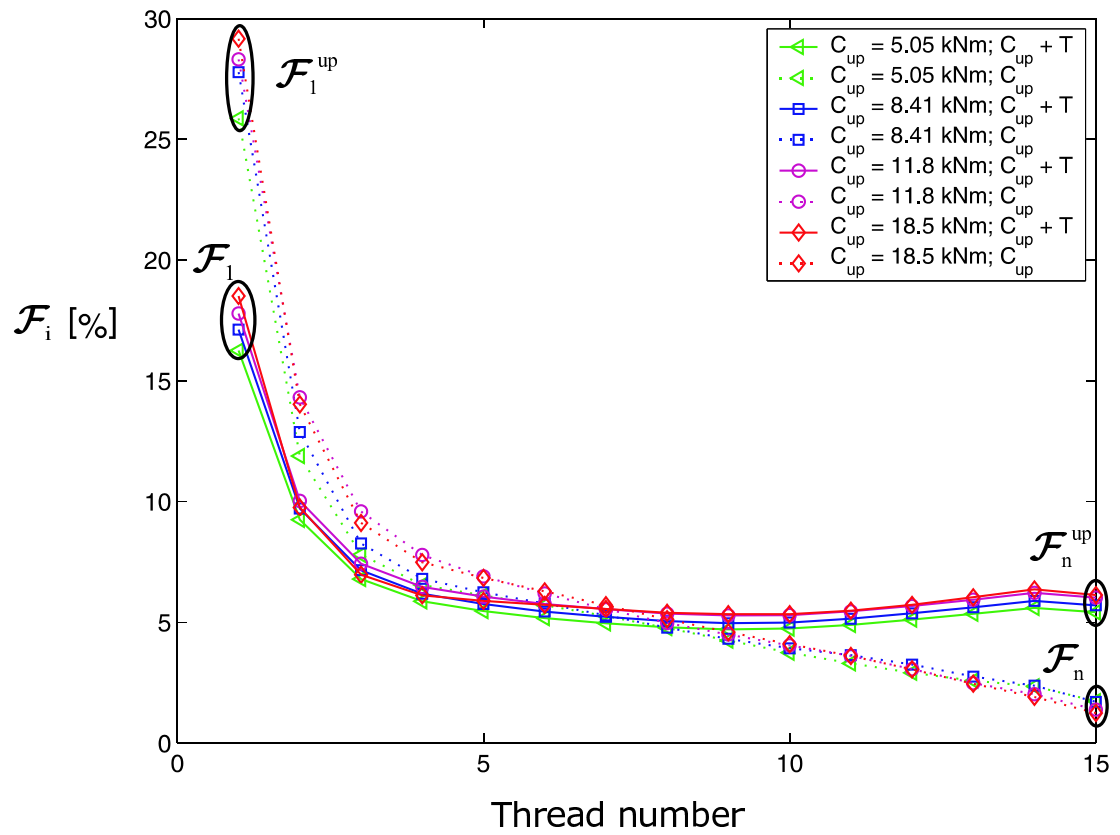

Figure 5. Load distribution in a threaded connection for traction loading.

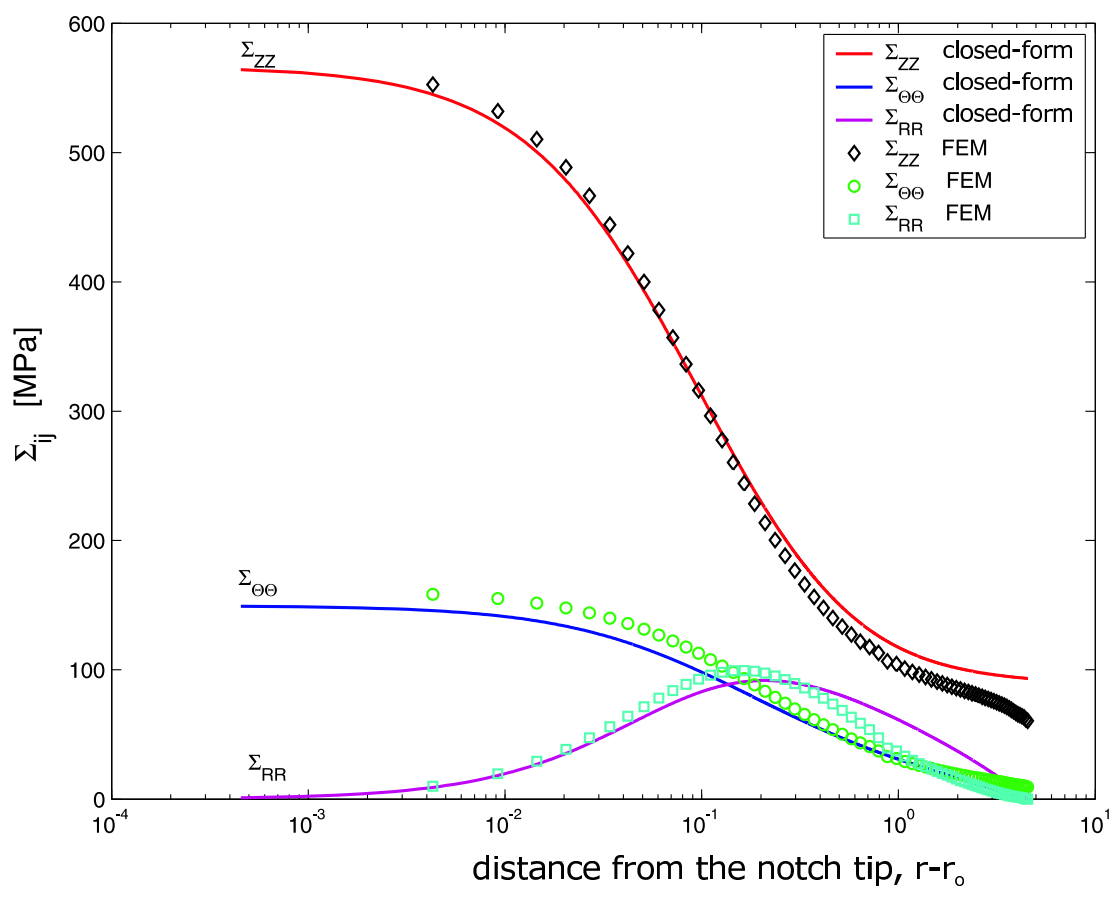

Figure 6. Comparison between FEM results and the closed-form solution of the stress components along the notch bisector as a function of the distance from the notch tip at the level of the root of the LET of the pin for tension loading with $C_{u p}=0 \mathrm{kNm}, \Sigma_{o}=30 \mathrm{MPa}$. and $r_{o}=0.1 \mathrm{~mm}$ 

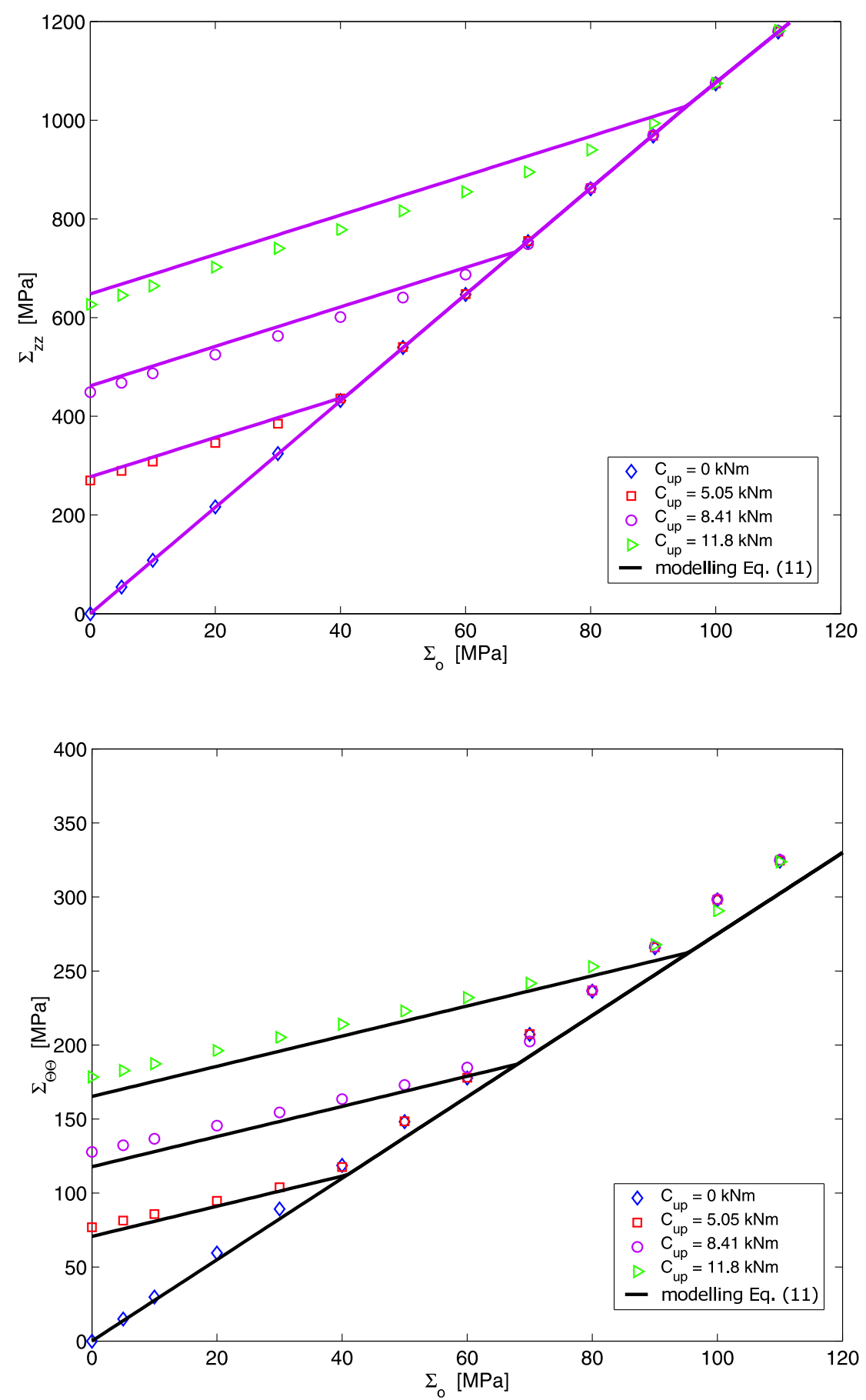

Figure 7. Comparison between FEM results and the closed-form solution for the stress component at the root of the LET of a threaded connection under traction loading. 

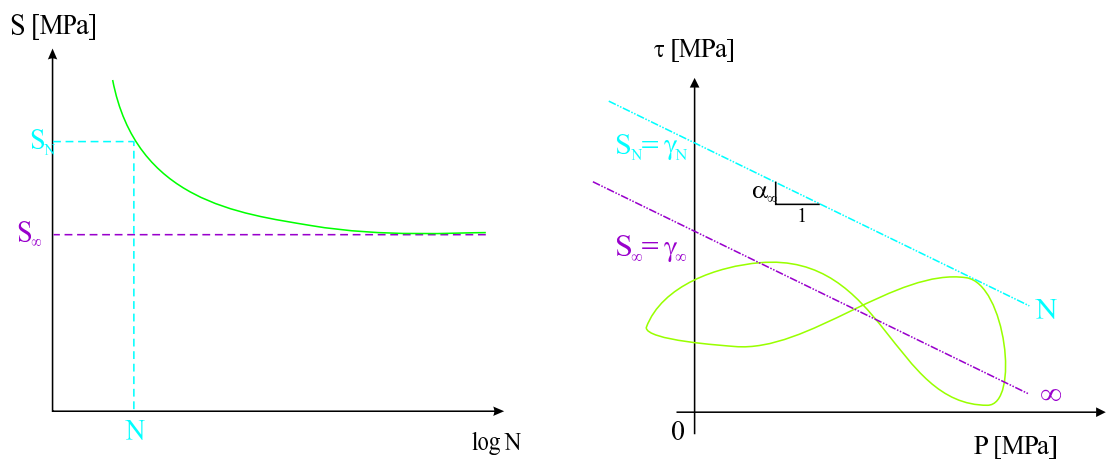

Figure 8. Extension of the Dang Van criterion for finite lifetime : a) Wöhler curve; b) Dang Van plot. 
a)

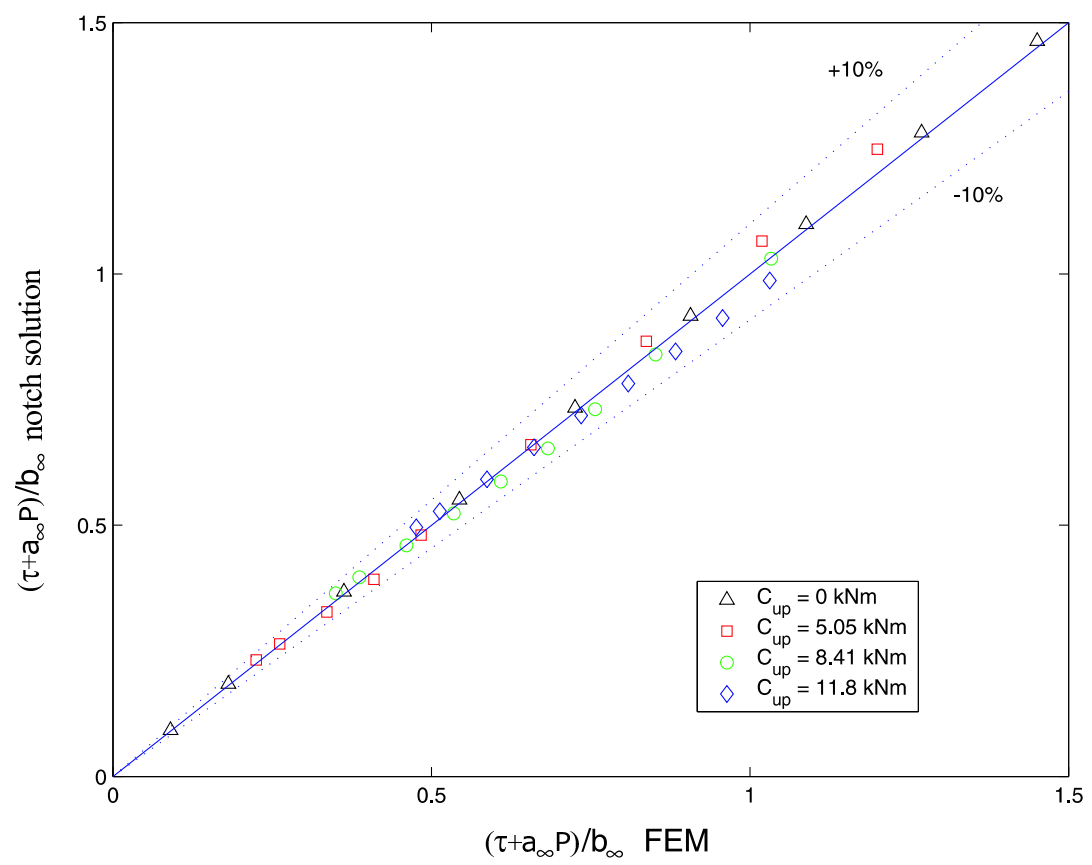

b)

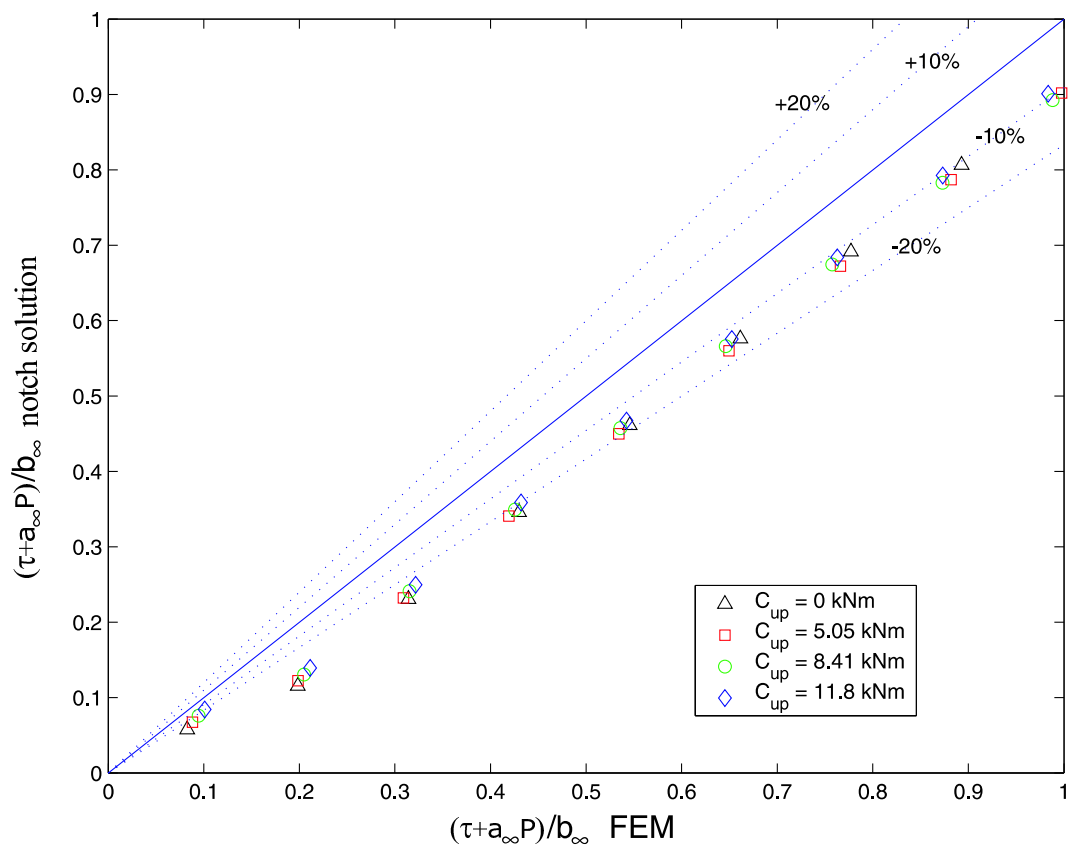

Figure 9. Comparison between the closed-form solution and the FEM results of the mesoscopic shear stress: a) at the root of the LET of the pin; b) at the root of the FET of the box. 


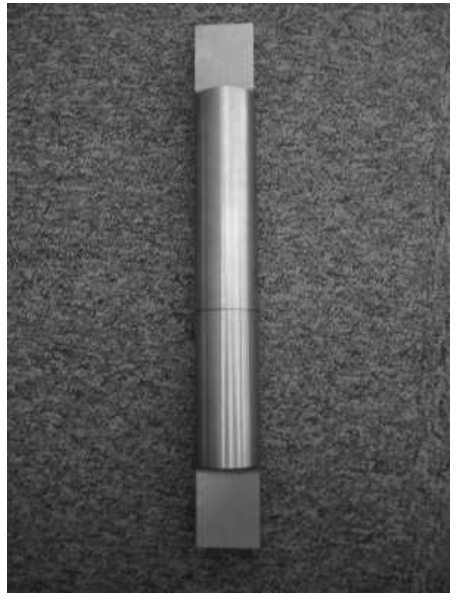

(a)

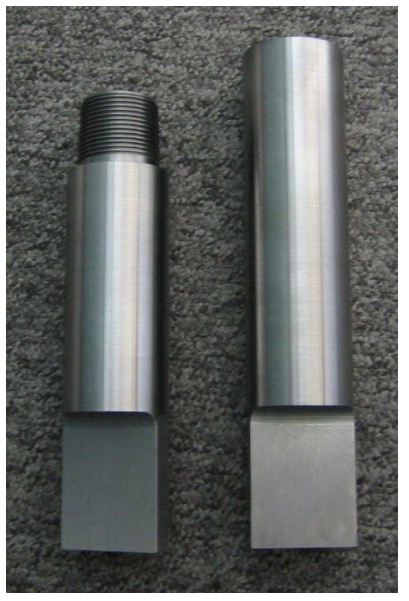

(b)

Figure 10. Photographies of the downsized threaded connection: (a) connected (b) pin and box

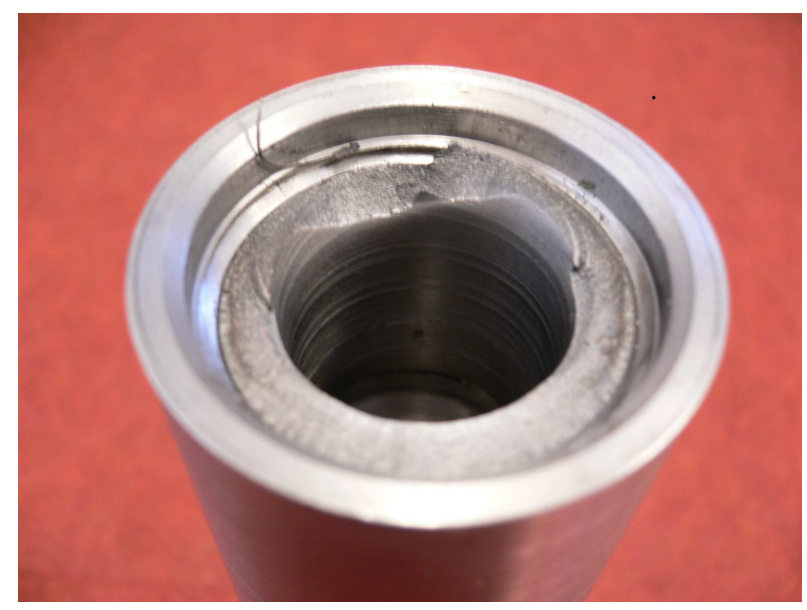

(a)

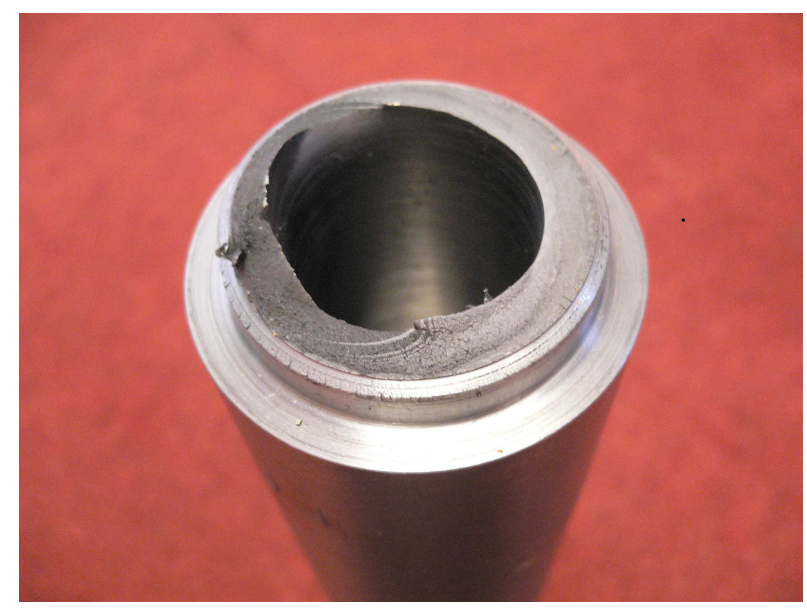

(b)

Figure 11. Photographies of the downsized threaded connection after failure: a) box b) pin. 


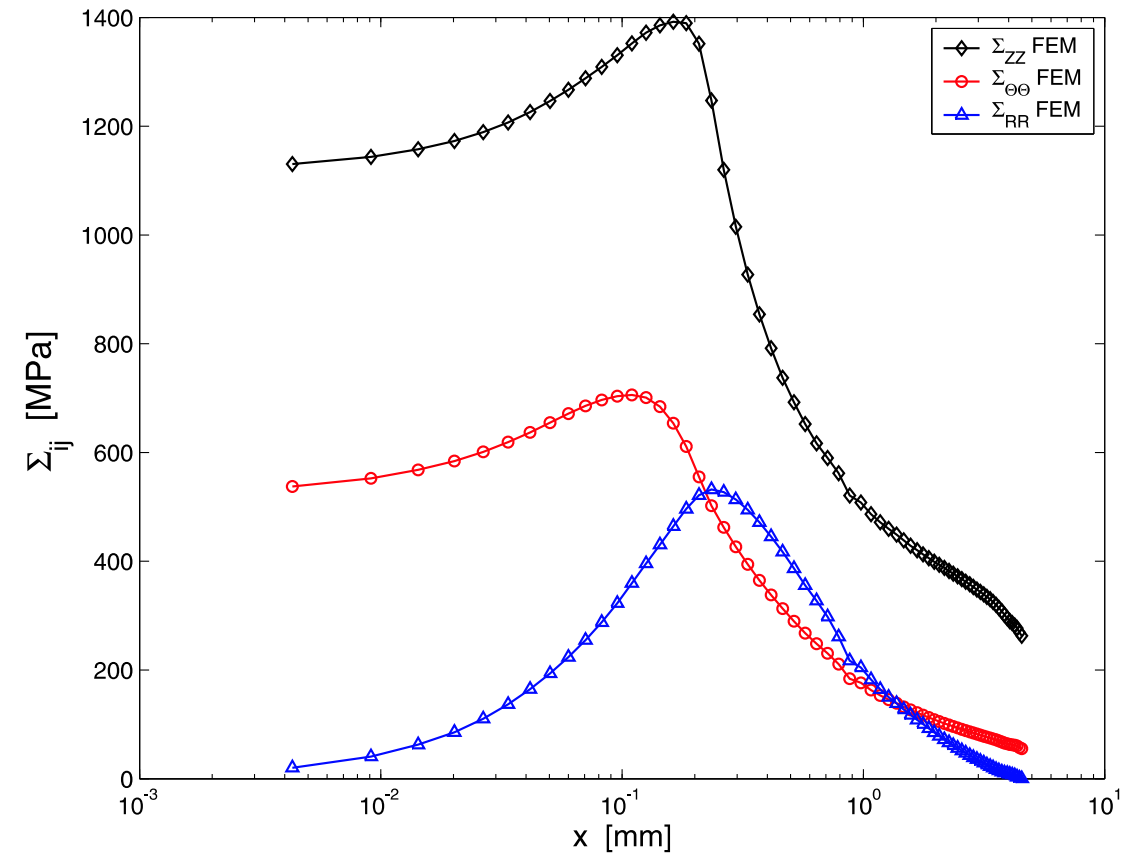

Figure 12. Stress distribution along the bisector of the root of the LET for $C_{u p}=433 \mathrm{Nm}$ and $T=113 k N$.

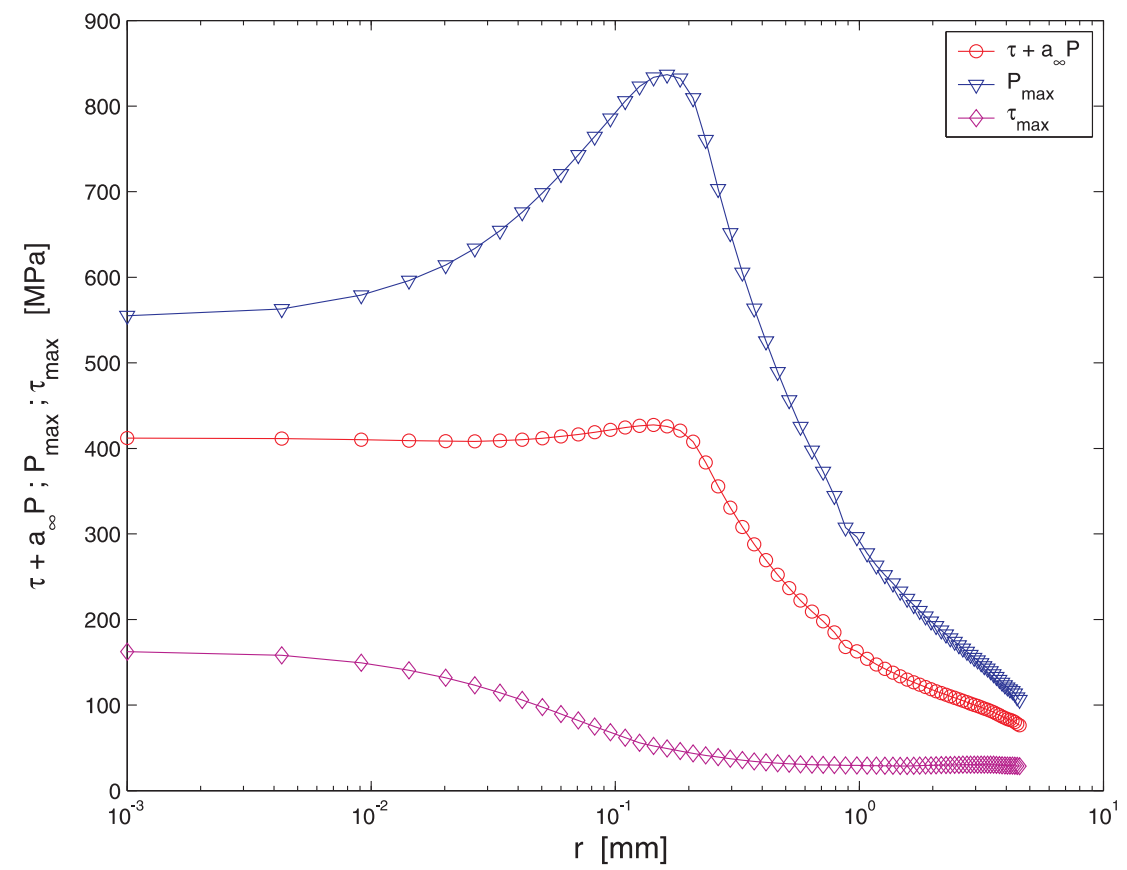

Figure 13. Distribution of the equivalent mesoscopic shear stress $\tau+a_{\infty} P$, the mesoscopic shear stress $\tau$ and the hydrostatic pressure $P$ along the bisector of the root of the LET for $C_{u p}=433 \mathrm{Nm}$ and $\mathrm{T}=113 \mathrm{kN}$. 


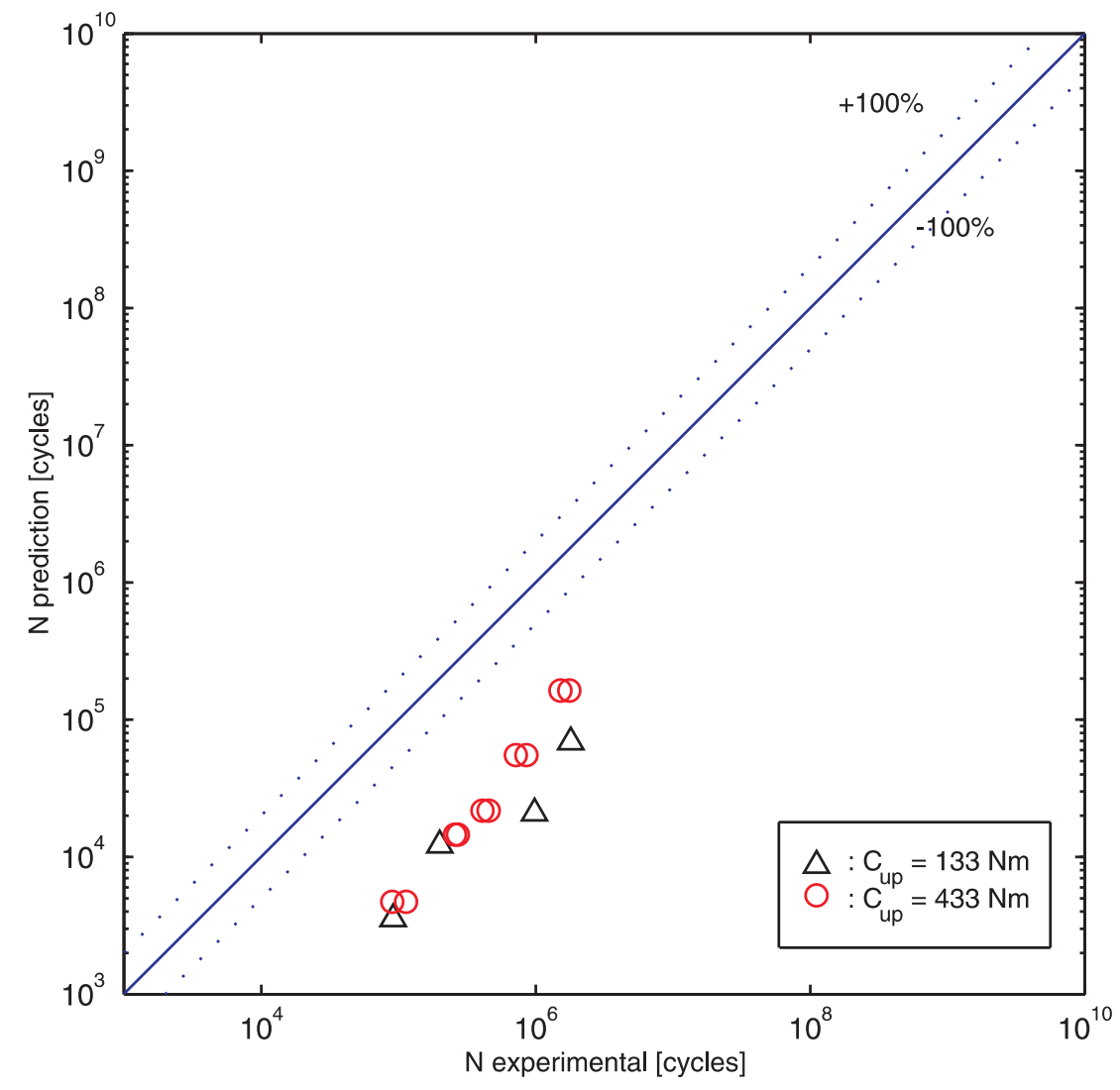

Figure 14. Comparison between the experimental and the predicted fatigue life using the Dang Van criterion. 


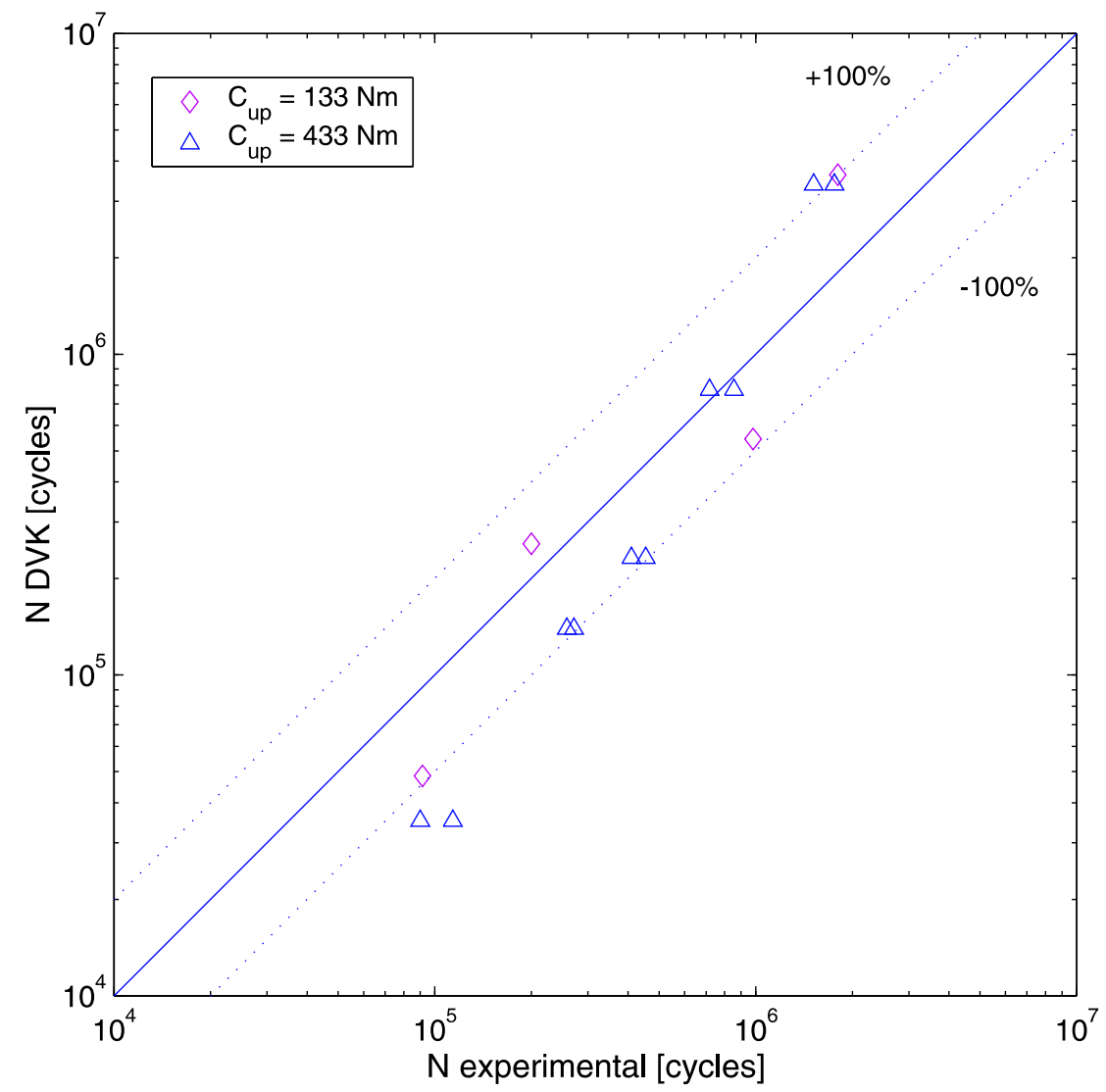

Figure 15. Comparison between the experimental fatigue life and the prediction with the use of the Dang Van criterion and a reduction of the stress field equal to $11 \%$. 